\title{
Mecânica celeste e a teoria dos sistemas dinâmicos: uma revisão do problema circular restrito de três corpos
}

Celestial mechanics and the theory of dynamic systems: a revision of the circular-restricted-three-body problem

\author{
Flavio Avila Correia Martins*1, Marcelo Zanotello² \\ ${ }^{1}$ Universidade Federal do ABC, Centro de Engenharia, Modelagem e Ciências Sociais Aplicadas, Santo André, SP, Brasil \\ ${ }^{2}$ Universidade Federal do ABC, Centro de Ciências Naturais e Humanas, Santo André, SP, Brasil
}

Recebido em 27 de Maio, 2017. Revisado em 25 de Agosto, 2017. Aceito em 02 de Outubro, 2017.

\begin{abstract}
Neste trabalho abordamos uma aproximação para o problema de três corpos que interagem mutuamente por atração gravitacional, denominada problema circular restrito de três corpos (PCR3C). Tal aproximação é revisada a partir do formalismo e de conceitos da teoria dos sistemas dinâmicos, enfocando fenômenos de ressonância, representações em espaços de fase, mapas de Poincaré e o Teorema KAM. Discutimos aspectos matemáticos de estabilidade do problema, seus pontos de equilíbrio - pontos Lagrangeanos - e como a condição de integrabilidade se aplica. Resultados de simulações computacionais que desenvolvemos são analisados e algumas aplicações são apresentadas, por exemplo, no que se refere à presença de regiões de comportamento caótico na seção de Poincaré, correlacionadas diretamente a vacâncias em cinturões de asteroides e nos anéis dos planetas gasosos do nosso sistema solar, bem como a possíveis transferências orbitais com menor custo energético.
\end{abstract}

Palavras-chave: problema de três corpos, teoria de sistemas dinâmicos, simulações, estabilidade.

In this work we present the approximation of the circular restricted three-body problem that interact by gravitation force, the so-called circular restricted three-body problem (CR3BP). Such model is reviewed starting from the formalism and concepts from the theory of dynamic systems, focusing on resonance phenomena, statespace representation, Poincare's maps and the KAM theorem. We have discussed mathematic stability aspects of the problem, its equilibria points - Lagrangean points - and how the integrability condition is applied to do so. Results from computational simulations are analyzed and some are presented, e.g., simulations that explore regions of chaotic behavior on the Poincare's section, directly correlated to the vacancies on asteroids belts and planet's rings from our solar system, as some possible orbit maneuvers that expends less energy.

Keywords: three-body problem, dynamic systems theory, simulations, stability.

\section{Introdução}

Conforme Monteiro (2011) [1], podemos considerar que a origem da denominada teoria dos sistemas dinâmicos coincide com a da mecânica clássica. O desenvolvimento da mecânica clássica, em especial na resolução de problemas envolvendo mecânica celeste, contribuiu fundamentalmente para a construção de conceitos e do formalismo constitutivo da teoria dos sistemas dinâmicos, que encontra aplicações atuais em diversas áreas do conhecimento. Inequivocamente, um marco na consolidação da mecânica clássica como um dos pilares da ciência moderna, foi a solução de Newton para o problema de Kepler referente às órbitas planetárias.

Em sua obra Princípios Matemáticos de Filosofia Natural, publicada pela primeira vez em 1687, Newton mostrou que um corpo esférico homogêneo, sujeito à ação de uma força atrativa central inversamente proporcional ao quadrado da distância entre ele e um corpo fixo, pode

*Endereço de correspondência: flavio.martins@outlook.com descrever uma trajetória elíptica como a identificada por Kepler no estudo da órbita de Marte. De fato, dependendo do valor da energia do sistema formado pelos dois corpos, a trajetória resultante da atração gravitacional mútua pode ser uma das seções cônicas: circunferência, elipse, parábola ou um dos ramos de uma hipérbole. Nesse cálculo, supõe-se que o corpo central está fixo por possuir massa consideravelmente maior do que o corpo que se move em relação a ele, de modo que quaisquer variações na energia potencial gravitacional do sistema manifestam-se exclusivamente sob a forma de energia cinética do corpo de menor massa [2]. Tal construção teórica explicou diversos aspectos da dinâmica dos movimentos de planetas e satélites observados em nosso sistema solar.

Quando se relaxa a restrição de que um dos corpos envolvidos esteja fixo, não mais considerando a massa de um deles muito maior que a massa do outro, formulase o chamado problema de dois corpos. Nesta situação, os dois corpos, interagindo gravitacionalmente entre si, 
estariam em movimento em relação a um referencial inercial. O problema de dois corpos possui solução analítica exata, sendo resolvido mediante uma transformação de coordenadas que faz uso das coordenadas do centro de massa do sistema de dois corpos e da distância relativa entre ambos. Isto significa que as equações diferenciais resultantes da aplicação das leis de Newton ao sistema de dois corpos podem ser resolvidas analiticamente, a fim de obter as posições dos corpos em função do tempo e, assim, determinar a dinâmica de seus movimentos. Nesse contexto, o sistema de dois corpos é classificado como integrável.

Avançando rumo à abordagens de maior complexidade, o problema seguinte a ser resolvido seria o de três corpos. Tal problema consiste em solucionar as equações que descrevem o movimento de três corpos assimiláveis a massas puntiformes ou esferas homogêneas, em um espaço tridimensional, considerando que estejam sujeitos apenas à atração gravitacional mútua. Porém, a despeito das muitas tentativas historicamente registradas, este se revelou insolúvel, no sentido de que não se consegue encontrar exata e analiticamente as equações diferenciais que governam seu movimento por meio de uma adequada transformação de coordenadas. Ou seja, não se obtêm expressões analíticas exatas que descrevam a trajetória de cada um dos três corpos gravitacionalmente interagentes e o sistema é classificado como não integrável. Diante desta dificuldade, foram propostas aproximações para simplificar o problema de três corpos e o tornar tratável de algum modo.

Uma aproximação consiste em assumir que a massa $m$ de um corpo é muito menor que as massas $M_{1}$ e $M_{2}$ dos outros dois; isto é: $M_{1} \sim M_{2} \gg m$, de forma que os efeitos gravitacionais de $m$ sobre $M_{1}$ e $M_{2}$ possam ser desprezados. Assim, o movimento dos dois corpos com maiores massas não são influenciados significativamente pelo terceiro, mas certamente o movimento de $m$ é influenciado pelos outros. Como exemplos de sistemas em que esta aproximação é razoável, podemos citar os sistemas Sol-Terra-Lua, onde a proporção das massas envolvidas é $3.10^{5}: 1: 10^{-2}$, e Terra-Lua-satélite artificial, com $10^{2}: 1: 10^{-19}[1]$. Nesta abordagem, o problema original é dividido em dois mais simples. Inicialmente, determinam-se os movimentos de $M_{1}$ e $M_{2}$ analiticamente, como no problema de dois corpos, o que permite encontrar um campo gravitacional resultante devido à esses dois corpos em cada ponto do espaço. Em seguida, calcula-se o movimento de $m$ sujeito à esse campo gravitacional resultante. Uma nova simplificação pode ser feita impondo que o movimento de $m$ seja restrito ao plano das trajetórias de $M_{1}$ e $M_{2}$ como consequência da conservação de seu momento angular.

Em 1772, Lagrange analisou o problema de três corpos com base nessa aproximação, tratando o caso em que $M_{2}$ é maior que $M_{1}$ e que ambos descrevem órbitas circulares em torno do centro de massa do sistema. Ele verificou a ocorrência de duas posições de equilíbrio estável na órbita de $M_{1}$. Relembrando o fato de que, de uma forma grosseira, um ponto de equilíbrio é dito estável quando, a partir de uma pertubação infinitesimal, o corpo tende à retornar ao estado de equilíbrio; é instável quando, na mesma situação, ele diverge do equilíbrio; e, no terceiro caso, um ponto de equilíbrio é dito neutro quando a pertubação infinitesimal o leva à um novo estado. Comumente, esta visão está associada ao exemplo do equilíbrio de uma esfera com energia mecânica dada pela combinação de energia potencial gravitacional e cinética. $\mathrm{O}$ ponto de equilíbrio estável seria obtido quando o corpo estivesse na parte central de uma calota esférica - com a sua concavidade voltada pra cima -, o equilíbrio instável, quando estivesse sobre o centro da calota esférica, mas esta estivesse com a concavidade voltada para baixo e, finalmente, o caso de equilíbrio neutro, quando a esfera estivesse sobre uma superfície plana.

Lagrange aplicou seu modelo supondo que $M_{2}$ representa o Sol e $M_{1}$, a Terra, com $M_{2} \gg M_{1}$. Os dois pontos de equilíbrio estável encontrados se situam sobre a órbita terrestre, na intersecção com as retas que formam ângulos de $+60^{\circ}$ e $-60^{\circ}$ em relação à reta que passa pelos centros de massa da Terra e do Sol. Nestes pontos, $m$ gira em volta de $M_{2}$ mantendo um ângulo fixo em relação à $M_{1}$, ou seja, $M_{1}, M_{2}$ e $m$ formam, em qualquer instante, um triângulo equilátero que gira com um vértice fixo em $M_{2}$. Além destes, Lagrange ainda encontrou outras três soluções de equilíbrio para o problema sobre a reta que atravessa os centros de massa de $M_{1}$ e $M_{2}$. Todo modo, estas três soluções de equilíbrio descrevem pontos de instabilidade no movimento.

No final do século XIX, diante da dificuldade em se encontrar soluções analíticas exatas para equações diferenciais como as decorrentes do problema de três corpos, Poincaré desenvolveu métodos que permitiam analisar qualitativamente o comportamento funcional da dinâmica do problema sem o conhecer explicitamente. Ele concluiu que as soluções em série normalmente empregues em problemas de mecânica celeste divergem, tornando-os não integráveis. Nas expansões em série, procuram-se por soluções que sejam formadas por uma soma infinita de termos, com cada termo sendo solução de uma versão simplificada da equação original. Conforme se adicionam mais termos à série, a aproximação à solução melhora e, se as correções à esta tendem à zero, a soma será finita e a mesma converge para a real. Neste método, típico das abordagens perturbativas, a expansão em série é feita em função de um parâmetro que deve ser pequeno. A ocorrência do caos no sistema está relacionada à questão da convergência destas séries 3 . Quando divergem, o sistema exibe comportamento caótico, caracterizado por movimentos aperiódicos, irregulares, limitados e sensíveis às condições iniciais.

Utilizando técnicas geométricas e topológicas, o trabalho de Poincaré tornou possível estudar determinadas propriedades de soluções desconhecidas, estabelecendo as bases para a construção da atual teoria de sistemas 
dinâmicos. Lyapunov, em 1892, definiu critérios de estabilidade para a solução de uma equação diferencial. Grosso modo, pode-se dizer que uma solução $x(t)$ é estável se outras soluções possíveis, cujos valores no instante $t_{0}$ estão próximos de $x\left(t_{0}\right)$, permanecem próximas de $x(t)$ com o decorrer do tempo. Por volta da metade do século XX, Kolmogorov, Arnold e Moser demonstraram que, a partir de certas condições iniciais, as séries de fato divergem, mas para outros conjuntos de condições inicias, elas convergem. Tal resultado, conhecido por teorema KAM, estabelece que, para um sistema de três ou mais corpos, o movimento pode ser regular ou caótico, em determinadas condições.

Neste trabalho, revisitamos o problema de três corpos em sua versão simplificada, conhecida por problema circular restrito de três corpos, à luz da atual teoria de sistemas dinâmicos, com o objetivo de fornecer ao leitor uma breve revisão de seus conceitos e formalismo básico, apresentando também os resultados de estudos numéricos que realizamos na busca por soluções das equações obtidas na formulação do problema.

\section{O problema circular restrito de três corpos (PCR3C)}

As hipóteses básicas do PCR3C são as seguintes: a massa do terceiro e menor corpo, cuja trajetória se deseja determinar, é desprezível; não existem outras fontes de perturbação externas e o primeiro corpo é tomado como referencial global do sistema. Valendo-se da conservação de momento angular, as órbitas são coplanares, sendo que a do segundo corpo em torno do primeiro (o mais massivo) é assumida como circular [3]. Desse modo, o sistema de equações diferenciais resultante da aplicação das leis de Newton é:

$$
\left\{\begin{array}{l}
\ddot{\mathbf{r}}_{1}=\frac{-G m_{2}\left(\mathbf{r}_{1}-\mathbf{r}_{2}\right)}{r_{12}^{3}} \\
\ddot{\mathbf{r}}_{2}=\frac{-G m_{2}\left(\mathbf{r}_{2}-\mathbf{r}_{1}\right)}{r_{21}^{3}} \\
\ddot{\mathbf{r}}_{3}=\frac{-G m_{2}\left(\mathbf{r}_{3}-\mathbf{r}_{1}\right)}{r_{31}^{3}}-\frac{G m_{2}\left(\mathbf{r}_{3}-\mathbf{r}_{1}\right)}{r_{31}^{3}}
\end{array}\right.
$$

Nas equações (1), os sub-índices denotam a sequência decrescente em massa de corpos do problema, sendo o primeiro o mais massivo, enquanto que $G$ corresponde à constante universal gravitacional. Efetua-se, agora, a seguinte mudança de variáveis [4]:

$$
\left\{\begin{array}{l}
M=m_{1}+m_{2} \\
L=\left|\mathbf{r}_{12}\right|=\left|\mathbf{r}_{21}\right| \\
n \equiv \text { freq. angular de }(X, Y) \\
\Omega=\frac{n^{2}}{2}(X+Y)+G\left(\frac{m_{1}}{\mathbf{r}_{31}}+\frac{m_{2}}{\mathbf{r}_{32}}\right)
\end{array}\right.
$$

Com as novas variáveis descritas em (2), $(X, Y)$ denotam as coordenadas globais do sistema, vide a Fig,1. enquanto que $n$ define a frequência angular de $X Y$ com relação a $x y$, fixo. Ambos centrados no corpo mais massivo. Além da mudança de variáveis definida em (2), novas são propostas e passam a reger o sistema:

$$
\left\{\begin{array}{l}
x=\frac{X}{L} ; y=\frac{Y}{L} ; t=n t^{\prime} \quad(a)(b)(c) \\
\mathbf{r}_{1}=\frac{\mathbf{r}_{31}}{L} ; \mathbf{r}_{2}=\frac{\mathbf{r}_{23}}{L}(d)(e) \\
\mu_{1}=\frac{m_{1}}{M} ; \mu_{2}=\frac{m_{2}}{M} ; \Omega_{a}=\frac{\Omega}{L^{2} n^{2}} \quad(f)(g)(h)
\end{array}\right.
$$

Nestas novas coordenadas, a constante gravitacional $G$ não mais aparece explicitamente. Substituindo as equações (3d) e (3p) em (1k) e empregando as demais condições descritas de (3a) à (3c), é possível se obter o seguinte conjunto de equações para a energia potencial rotacional:

$$
\left\{\begin{array}{l}
\frac{\partial \Omega}{\partial x} \equiv \Omega_{x}=\ddot{x}-2 \dot{y} \\
\frac{\partial \Omega}{\partial y} \equiv \Omega_{y}=\ddot{y}+2 \dot{x}
\end{array}\right.
$$

Notando que $M=1, n=1$ e $T=2 \pi$. Tomando as variáveis explicitadas pela Fig, 1 , no sistema sideral, define-se a seguinte quantidade [5]:

$$
C_{j}=s\left(\frac{\mu_{1}}{r_{1}}+\frac{\mu_{2}}{r_{2}}\right)+2 n(\xi \dot{\eta}-\eta \dot{\xi})-\left(\dot{\xi}^{2}+\dot{\eta}^{2}+\dot{\zeta}^{2}\right)
$$

Onde $\eta$ e $\xi$ denotam novas coordenadas generalizadas, de forma que o vetor que posiciona o terceiro corpo com relação ao novo referencial é dado por $\mathbf{r}=(\xi, \eta, \zeta)-$ sendo $\zeta$ nulo no caso coplanar - no que se chama por sistema sideral, vide a Fig.1. A relação em (6) pode ser demonstrada de (4) e (5), usando $\Omega$ em coordenadas cartesianas:

$$
\Omega(x, y)=\frac{n^{2}}{2}\left(x^{2}+y^{2}\right)+\frac{(1-\mu)}{r_{1}}+\frac{\mu}{r_{2}}
$$




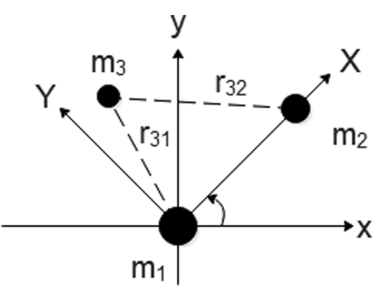

(a)

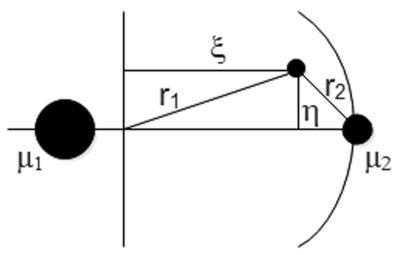

(b)

Figura 1: (a) Representação das variáveis originais do PCR3C. (b) Representação do sistema sideral.

De modo que $C_{J}$ será dado por:

$$
2 \Omega-C_{j}=\dot{x}^{2}+\dot{y}^{2}
$$

A Integral de Jacobi, $C_{J}$, na expressão (5) é derivada diretamente da mudança de variáveis do sistema expresso em coordenadas cartesianas, por (1), para aquelas no sistema sideral, de modo que ainda se preserva a relação de ser a energia total por unidade de massa de um sistema rotacional a menos de duas vezes a energia potencial, em (6), com as componentes cinética, centrífuga e gravitacional incluídas, vide (5).

Finalmente, considerando a massa reduzida $\mu$, em (6), é possível mostrar que o centro de giro $X Y$ serve como baricentro das duas primeiras massas, de tal modo que a primeira estará distante $\mu$ de $(x, y)=(0,0)$, e a segunda, $(1-\mu)$. Uma vez que $\Omega$ é a energia potencial do sistema $[6]$, é possível verificar a relação (7) a partir das equações (4) à (6).

\subsection{Pontos Lagrangeanos no PCR3C}

Considerando que a energia potencial do sistema é a própria função $\Omega$, os pontos de equilíbrio de (4a) podem ser calculados ao se fazer (4b) e (4) iguais a zero, como 7]:

$$
\left\{\begin{array}{l}
\Omega_{x}=x-(1-\mu) \frac{(x+\mu)}{r_{1}^{3}}-\mu \frac{(x-1+\mu)}{r_{2}^{3}}=0 \\
\Omega_{y}=y-\frac{(1-\mu) y}{r_{1}^{3}}-\mu \frac{y}{r_{2}^{3}}=0
\end{array}\right.
$$

A solução não trivial de (8p) é dada por:

$$
\frac{\mu}{r_{2}^{3}}-\frac{1+\mu}{r_{1}^{3}}=1
$$

A solução geral (9) fornece a disposição de dois pontos de equilíbrio estável para o sistema, conhecidos por $L_{4} \mathrm{e}$ $L_{5}$, pontos Lagrangeanos. Outras três soluções podem ser obtidas de (8a), expressas na Fig.2 Desa forma, tomamse os cinco pontos de equilíbrio para a energia potencial do sistema.

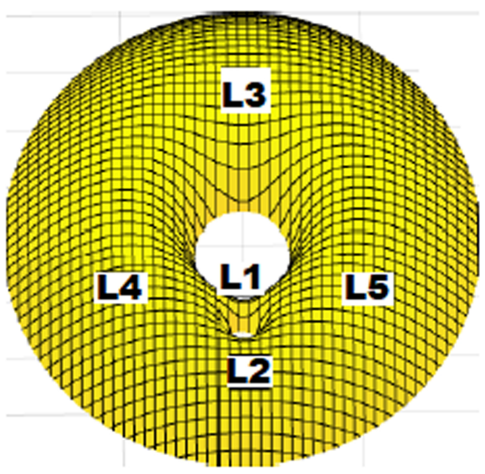

Figura 2: Representação dos cinco pontos Lagrangeanos do PCR3C. A figura foi gerada a partir da sobreposição das curvas de energia potencial e centrífuga simuladas para um binário $M_{1}=1000 M_{2}$.

\subsection{Energia, Regiões e Hill e Mapa de Poincaré}

O estudo das curvas de energia potencial efetiva permite determinar as regiões do espaço de fase - e, inclusive, geométricas - onde um corpo pode ou não ser encontrado. Tomando como exemplo um sistema com duas coordenadas generalizadas e dois momentos generalizados associados à estas: ao se fixar um desses dois pares, e.g., $\left(p_{2}^{*}, q_{2}^{*}\right)$, e dar uma determinada condição inicial para as outras duas variáveis de estado, digamos, $\left(p_{1, i}, q_{1, i}\right)$, a partir da qual se evoluirá no tempo, a dinâmica do sistema pode ser registrada em um mapeamento bidimensional sobre um plano descrito pelas duas primeiras variáveis de estado. O problema de avaliar um sistema 4-dimensional, com suas infinitas possibilidades de mapeamento, se limita àquele de visualizar o encontro, i.e., o cruzamento, das variáveis livres com o plano descrito pelas variáveis fixas. Os pontos nos quais ocorre tal cruzamento denotam aquilo que se chama por mapeamento $P$ das Seções de Poincaré.

Uma forma prática de encarar tal metodologia consiste em imaginar que para se avaliar a topologia de um corpo pode ser suficiente enxergar apenas a sua projeção no plano: toma-se uma representação bidimensional capaz de resguardar algumas características importantes do sistema real - difícil de analisar diretamente. Visualmente, o processo pode ser interpretado, também, como o de secionar um corpo sólido: se o espaço de estados de um sistema descrevesse uma região tridimensional, o processo seria o equivalente a realizar um corte na seção 
transversal desse corpo e registrar todos os pontos que fizeram intersecção com a superfície obtida.

Todavia, se existem tais regiões, o mapeamento $P$ do espaço de fases também deverá ser limitado. Dentro do espaço de fase 4-dimensional do problema restrito de três corpos existe uma superfície tridimensional na qual $P$ pode ocorrer. Dada a energia total e o fato de que, em sistemas conservativos, esta é igual à Hamiltoniana [6], essa superfície pode ser definida de duas formas:

$$
\begin{aligned}
& M(E, \mu)=\left\{\left(x, y, p_{x}, p_{y}\right) \mid H\left(x, y, p_{x}, p_{y}\right)=E\right\} \\
& M(E, \mu)=\{(x, y) \mid \Omega(x, y) \leq E\}
\end{aligned}
$$

Fisicamente, 10 nos diz que as regiões nas quais o mapeamento pode ocorrer são limitadas pela condição de energia potencial menor ou igual a energia total do sistema. Isso é fácil de inferir, em vista de que a energia cinética será sempre não negativa. Assim, não existe outra possibilidade que se não a de ter valores de energia potencial menores (ou iguais) a energia total. Como exemplo de uma região na qual se pode mapear o espaço de fase do sistema, tomam-se as coordenadas dos pontos Lagrangeanos $L_{4}$ ou $L_{5}$, cuja energia potencial é solução de equilíbrio e pode ser feita tal que $\Omega=E$, resultando em:

$$
\Omega=E=-1,5+\mu(1-\mu)
$$

Desse modo, a expressão (11) é útil para descrever o contorno exigido por 10 , denominado por Região de Hill. Tomando a energia total do sistema como o somatório de componentes de atração gravitacional e força centrífuga do movimento rotacional para o ternário, o que se obtêm são cortes secionais da região exibida na Fig,2, cujos pontos críticos são os pontos Lagrangeanos. Neste caso, imagine um sistema cuja energia total $E$ é um valor elevado. O conjunto descrito por (11) será menos restritivo, permitindo ao terceiro corpo assumir um maior número de estados, podendo ocupar mais regiões do espaço com uma maior gama de momentos lineares associados.

Como exemplos de regiões permitidas, tomam-se cinco medidas de energia total $E$ para o sistema, conforme a Fig, 3 onde se representam as regiões permitidas pela coloração branca, as proibidas, por cinza, os centros de massa, por pontos pretos e os pontos de equlíbrio, pontos cinza-escuro. Fica evidente que para valores mais elevados de energia mecânica, caso da figura superior esquerda, o movimento é praticamente irrestrito, enquanto que para valores menores, como é o caso da figura inferior esquerda, ficará retido à uma órbita em torno de $M_{1}$ ou $M_{2}$.

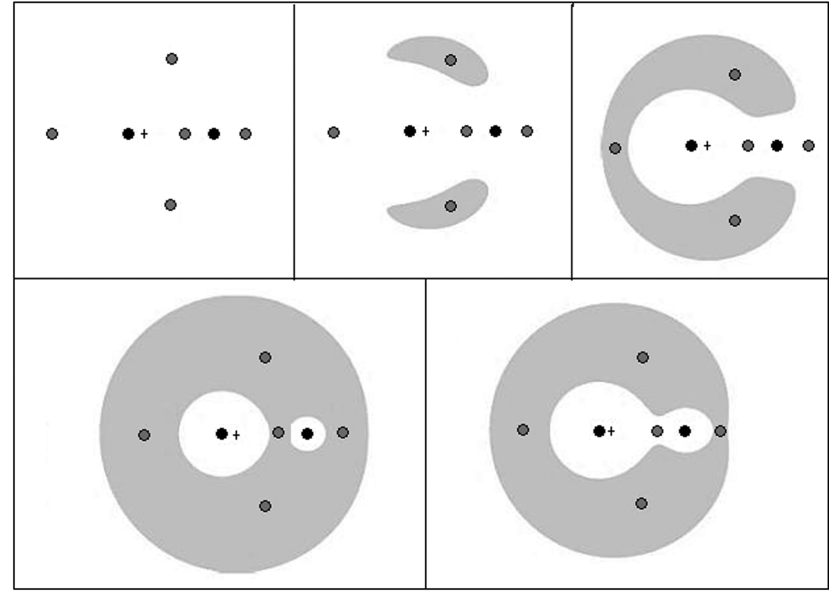

Figura 3: Regiões proibidas (em cinza) e regiões de Hill (permitidas, em branco) para a vista no plano da órbita, para cinco medidas de energia total $E$. Os pontos pretos representam os centros de massa e os cinza-escuro, os pontos Lagrangeanos. A energia descresce da esquerda para a direita, na linha superior, e da direita para a esquerda, na linha inferior. Sendo o valor máximo adotado para a figura superior esquerda e o mínimo, na figura inferior esquerda.

Outro resultado interessante dessa análise consiste em enxergar que para um corpo sujeito à dissipação da sua energia total, o que é o caso real, as regiões permitidas perdem área e levam o sistema à órbitas fechadas em torno dos dois corpos mais massivos. Quão menor a medida desta energia, menor o semi-eixo maior da elipse descrita, fazendo com que as órbitas fechadas geradas decaiam, o que é outra forma de interpretar o problema de perda de altitude de órbitas de satélites, por exemplo.

De fato, infinitas superfícies permitidas podem ser eleitas, sendo a metodologia de solução a descrita nestes últimos parágrafos. Segundo Worthington (2012) 7], existe outra superfície de interesse, mapeada da seguinte maneira: $y=(x+\mu)^{1 / 3}$ e $0.5\left(p_{x}-p_{y}\right)^{1 / 3} \geq 0$. Nesta condição, obtém-se uma linha que passa pelo ponto $(-\mu, 0)$, centro de massa do primeiro corpo, e $L_{4}$, o que será empregue posteriormente.

A representação por seções de Poincaré nos permite observar a tendência à estabilidade ou instabilidade de um sistema, conforme será discutido. Não obstante, até mesmo sistemas com três graus de liberdades que sejam reduzidos à análise de uma seção de Poincaré serão estáveis caso o mapeamento desses o seja [8]; e serão instáveis caso contrário, i.e., a tendência à estabilidade ou ao caos do sistema descrito no PCR3C podem ser garantidas apenas pela análise da seção de Poincaré.

\subsection{Teorema KAM e sistemas quase-integráveis}

Feitas as considerações anteriores, introduz-se o Toerema KAM e a mudança de variáveis para as do tipo Ângulo-Ação. Antecipa-se que a grande vantagem de tal procedimento está relacionada ao fato de que, nestas novas variáveis, é possível se representar a dinâmica do sistema a partir e um mapeamento em forma de toro. 
Estes toros, caso perturbados, terão sua topologia e mapeamento concomitantemente distorcidos, dando lugar ao que se chama de Superfície KAM. A distorção, ou completa destruição, desses toros e superfícies KAM, i.e., do mapeamento do espaço de fase do sistema, está diretamente associada ao fenômeno do caos (estabilidade e instabilidade) e ressonância, justificando a aplicação do método.

Seja um sistema descrito pelas variáveis ângulo e ação, conforme a expressão 12 , onde à Hamiltoniana do sistema não perturbado, $H_{0}$, é adicionada uma Hamiltoniana perturbada, $H_{1}$, multiplicada por uma constante $\epsilon$ que a pondera:

$$
K(I, \phi)=H_{0}(I)+\epsilon H_{1}(I, \phi)
$$

As variáveis ângulo e ação permitem à dinâmica do sistema perfazer toros no espaço de fase, de tal modo que a variável ação $I$ é calculada por $(13$ a) e a variável ângulo, $\phi$, evolui segundo $(13 \mathrm{~b})$, onde $\omega$ é a frequência natural do sistema.

$$
I_{i}=\frac{1}{2 \phi} \oint p_{i} \cdot d q_{i}(a) \quad e \quad \phi(t)=\omega\left(I_{0}\right) t+\theta_{0}(b)
$$

Em (13a), $q$ são as coordenadas generalizadas e $p$, os momentos associados à estas coordenadas generalizadas. A representação a partir destas variáveis só é possível caso o sistema seja integrável [3], mas é particularmente vantajosa por nos permitir empregar a representação em toros, definida da seguinte forma: o primeiro conjunto $\left(I_{1}, \phi_{1}\right)$, tem $I_{1}$ como o raio de uma circunferência cujos pontos no espaço de fase rotacionam segundo $\phi_{1}$. A seção definida por esta circunferência, por sua vez, gira com um raio $I_{2}$ e ângulo $\phi_{2}$, associados à transformada $\left(p_{2}, q_{2}\right) \rightarrow$ $\left(I_{2}, \phi_{2}\right)$ [9]. O resultado desta operação descreve um toro no espaço de fase, conforme representado na Fig, 4 nos quais os estados de um sistema não perturbado serão marcados.

Notavelmente, isso significa que sistemas não perturbados terão o mapeamento em espaço de estados com a topologia de um toro - da definição de seção de Poincaré, como circunferências perpendiculares a um plano $\left(I_{2}, \phi_{2}\right)$

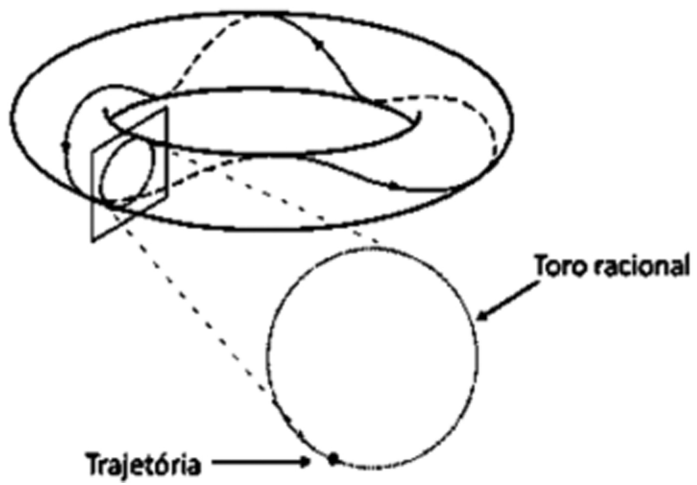

constante -. Assim, a parte integrável da Hamiltoniana $K$, $H_{0}$, do PCR3C poderia ser analisada em sua estabilidade a partir de apenas uma dessas coordenadas, transformadas em variáveis ângulo-ação, e este resultado deveria nos retornar um mapeamento $P \in\left(I_{1}, \phi_{1}\right)$ na seção de Poincaré. Todo modo, a existência de um termo perturbativo coloca em discussão a existência desse toro, dado que o sistema não mais é integrável e a transformação para variáveis ângulo e ação não ocorreria. Neste caso, o sistema poderia ser estável ou não, dado que a teoria para sistemas Hamiltonianos integráveis não mais se aplicaria. Nesta situação, recorre-se ao teorema KAM para encontrar uma resposta para a dinâmica de um sistema perturbado.

Retomando a definição dos toros no espaço de fase, tome uma situação na qual o mapeamento do sistema associado a 13 ocorre segundo:

$$
\left\{\begin{array}{l}
I_{(1, j+1)}=I_{j}+\epsilon f\left(\phi_{1, j}, I_{1, j}\right) \\
\phi_{1, j+1}=\phi_{1, j}+2 \pi \alpha\left(I_{1, j}\right)+\epsilon g\left(\phi_{1, j}, I_{1, j}\right)
\end{array}\right.
$$

Em (14) fica evidente que se $\epsilon=0$, o sistema permanecerá sempre em um estado de movimento para $\alpha I_{1, j}=\omega_{1} / \omega_{2}=1$ ou $\alpha I_{1, j}=a / b \neq 1$, sendo que no segundo caso ele será mapeado na seção de Poincaré rotacionando à um raio $I_{1, j+1}$ constante, mas evoluindo por um ângulo $\phi_{1, j+1}=2 \pi(a / b)$ à frente do ponto anterior, descrevendo, assim, uma circunferência que volta a se fechar após $b / a$ rotações. Nesse ponto, o Teorema KAM contribui por garantir que estes mesmos efeitos podem acontecer, sim, para a Hamiltoniana perturbada $K$ desde que se garantam duas condições:

$$
\begin{aligned}
& \text { i. } \quad \epsilon \ll \frac{\left|H_{0}\right|}{\left|H_{1}\right|} \\
& \text { ii. } \quad r \omega_{1}-s \omega_{2} \neq 0
\end{aligned}
$$

Em suma, o teorema KAM garante que a transformação para variáveis ângulo e ação ocorrerá para sistemas perturbados desde que, de (15), o termo perturbativo seja suficientemente menor que o não perturbado, e de que o resultado mais valioso - não se possa encontrar $r, s \in \mathbb{Z}$,

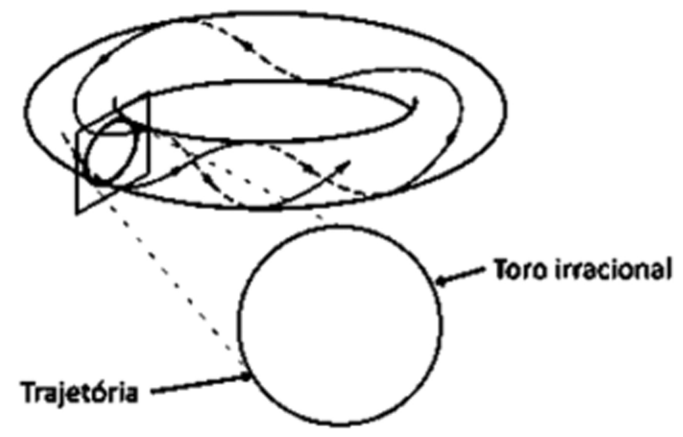

Figura 4: Toros racionais e irracionais, associados à um sistema não perturbado. Figuras retiradas e adaptadas de [10]. 
de tal forma que a razão entre as frequências angulares associadas à primeira e segunda coordenadas generalizadas seja racional. O teorema é também capaz de definir um limite para a irracionalidade do sistema que ainda permite garantir a existência da transformada para variáveis ângulo e ação, dada por:

$$
\left|r-\frac{s_{j}}{r_{j}}\right|>c(\epsilon)\left(r_{j}\right)^{-5 / 2}
$$

Tenha a razão entre a primeira e a segunda frequências angulares dadas por um valor $r$ qualquer. Neste caso, para $s_{j}$ e $r_{j}$ números inteiros, 16 nos diz que a representação por um toro ainda será válida desde que a razão $r=\omega_{1} / \omega_{2}$ entre frequências naturais seja suficientemente irracional, i.e., mal aproximada por um número racional, e que esta irracionalidade é dimensionada por uma função $c(\epsilon)$ que depende da razão entre energias (Hamiltonianas) perturbada e não perturbada. Caso a relação seja obedecida, garante-se a existência de toros distorcidos, as superfícies KAM.

Retornando à discussão de racionalidade, toros não perturbados podem ser racionais ou irracionais, conforme as taxas às quais os pontos no diagrama de fase são mapeados. Assim, tenha $\alpha \equiv \omega_{1} / \omega_{2}=r / s \mid r, s \in \mathbb{Z}$. Ao aplicar uma matriz de rotação a um vetor $\left[q_{i}, p_{i}\right]^{T}$, não é difícil notar que o sistema irá à um estado $\left[q_{i+1}, p_{i+1}\right]^{T}$ dado por:

$$
\left\{\begin{array}{c}
q_{i+1} \\
p_{i+1}
\end{array}\right\}=\left[\begin{array}{cc}
\cos (2 \pi \alpha) & \operatorname{sen}(2 \pi \alpha) \\
-\cos (2 \pi \alpha) & \cos (2 \pi \alpha)
\end{array}\right]\left\{\begin{array}{c}
q_{i} \\
p_{i}
\end{array}\right\}
$$

Toros racionais serão aqueles nos quais a evolução ocorre segundo (17). Tenha, agora, o caso no qual $\alpha=$ $\alpha\left(I_{1}\right)$, de tal forma que o mapeamento $P$ na seção de Poincaré passa a ser dado por $P(s \alpha)=1$. Definindo o mapa de torção por $T_{0}(\alpha)=P(s \alpha)$, um resultado muito importante para entender a dinâmica dos toros e das superfícies KAM se encontra: retomando (14a) e $(14 \mathrm{~b})$, para o caso no qual $\epsilon=0$, então, para uma determinada razão de frequências angulares, define-se $\alpha^{*}=\alpha\left(I^{*}\right)=1$. Esta condição descreve um toro irrotacional, i.e., seus estados são remarcados com as mesmas coordenadas, não importando a iteração presente do sistema.

Imagine que um valor novo de $I$ seja tomado como $I>I^{*}$. Em tais circunstâncias, de (14a), a nova seção de Poincaré passará a ser demarcada por uma circunferência de raio maior. Todo modo, os pontos que estão à distâncias maiores que a definida pelo toro irrotacional têm a progressiva tendencia à girarem no sentido antihorário, e o caso contrário para aqueles à distâncias menores. Assim, evidencia-se o movimento de torção de uma superfície excêntrica. Em perfis circulares - movimento não perturbado - todos os seus pontos rotacionariam à uma taxa única, não apresentando o efeito, mas caso uma mesma topologia abranja diferentes valores de $I$, seus pontos tenderão à rotacionar em sentidos e taxas diferentes conforme esta cruzar a faixa de $I^{*}$.
Tomando a situação na qual se traça o mapa de torção de toros deformados, conforme a Fig 5 (b). Partindo da curva original, $R_{e}$, sua evolução no tempo resulta na nova seção transversal, $T\left(R_{e}\right)$, conforme representado. Os pontos interiores ao toro não rotacional (associado a $I^{*}$ ) girarão no sentido horário, enquanto os exteriores, no sentido anti-horário. Todo modo, não é difícil de notar que a dimensão das superfícies são proporcionais à energia do sistema (basta retomar à equação de transformação para as variáveis ângulo-ação), o que indica que, independente de como se distorça a superfície, ela deverá preservar a sua área inicial. Portanto, existirá a composição de dois tipos de movimento: o giro dos pontos ao serem remapeados e a concomitante distorção das seções pela preservação da energia mecânica. Assim, em superfícies com maiores distorções, mais complexas e desregulares serão as remarcações dos estados, até o ponto no qual a pertubação supera a tendência à regularidade da dinâmica e seu movimento dê lugar ao comportamento errático, i.e., caótico, com a destruição da superfície KAM associada.

Todo modo, ainda existirão pontos no mapa de torção que permanecerão irrotacionais, nomeados por $A 1, A 2$, $B 1$ e $B 2$, na Fig 5 (c). Neste caso, existirão $2 s$ pontos não rotacionais, sendo s definido como em (16). Isto significa que, para um mapeamento ocorrendo à uma taxa $s, 2 s$ pontos serão remarcados em seu próprio lugar. A implicação direta disso é que não apenas se destroem as superfícies KAM que cruzam toros racionais (toros que são irrotacionais a cada $s$ evoluções), mas que a dinâmica desta destruição cria um número par de pontos nos quais a dinâmica dá lugar à novos tipos de movimento periódicos. Fica evidente que quão mais longe as superfícies KAM estiverem dessas regiões de existência de toros racionais, menor será o efeito sobre seus pontos ao sofrerem evolução. Esta é outra forma de enxergar a estabilidade e instabilidade dinâmica de sistemas: toros ressonantes (ou racionais) torcem as curvas de evolução dos pontos no espaço de estado, fazendo com que, quão mais perto as superfícies KAM estiverem deles, maior o efeito e, consequentemente, a tendência à destruição completa do perfil, levando ao caos. Além disso, notase que se não houvesse a perturbação, não existiria a deformação na superfície e, consequentemente, não haveria o cruzamento. Assim, sistemas não perturbados não apresentariam o efeito.

Devido à simetria do problema, os pontos B na Fig. 5 (c) servirão de centro de rotação para o mapeamento de pontos vizinhos, isto é, darão origem à novos toros. Isso quer dizer que a destruição de uma superfície próxima da região de um toro racional de frequência $s$, gerará $s$ toros secundários. Esses pontos são chamados de estáveis, enquanto a variedade $A$, na mesma figura, são instáveis - mas não necessariamente o movimento será instável ao redor destes. Para entender a dinâmica em torno da variedade $A$, toma-se a Fig.5(c), onde se expôs $W_{s}$ e $W_{u}$, curvas invariantes no espaço. Essas têm as seguintes 


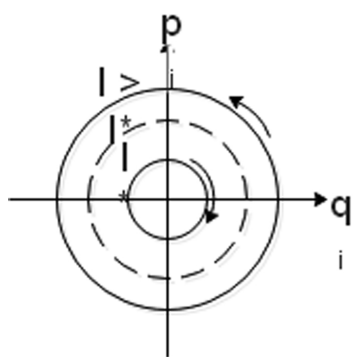

(a)

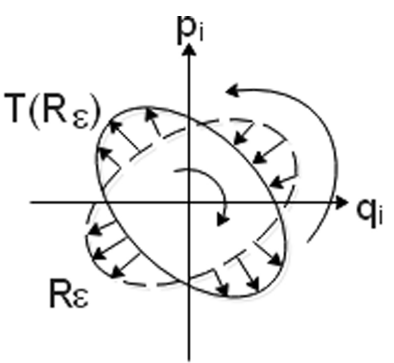

(b)

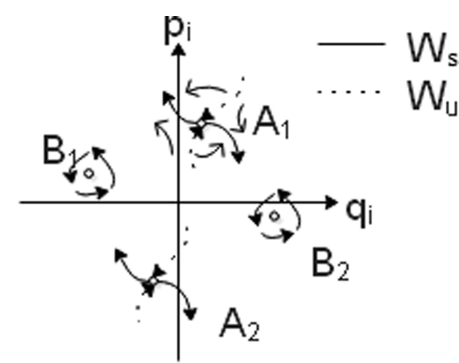

(c)

Figura 5: (a) Mapeamento para seção de Poincaré de toros não perturbados. (b) Mapeamento para toros perturbados. (c) Formação de toros secundários.

definições: a variedade $W_{s}$ é considerada estável, ou seja, é um conjunto de órbitas que, para um comportamento assintótico (mapa de torção iterado infinitas vezes), voltam ao ponto inicial. Já $W_{u}$ é a variedade instável, que constitui um conjunto invariante de pontos do espaço de fase cujas curvas propagadas para trás no tempo fazem com que o mapa de torção retorne ao ponto inicial. Em outras palavras, $W_{s}$ é um conjunto de pontos que, para $n \rightarrow \infty$, têm um mapa de torção que faz com que o ponto volte a ser igual ao inicial, e $W_{u}$, para $n \rightarrow-\infty$. Na Fig.5(c), $W_{u}$ são curvas que "saem" do ponto, e $W_{s}$, que "entram".

A conclusão disso é que a destruição de superfícies KAM em torno de toros racionais, de frequência de mapeamento $s$, dará origem à $2 s$ pontos irrotacionais, dos quais metade iniciam toros secundários e a outra metade pode apresentar movimento caótico ou servir de um novo centro para a dinâmica do sistema, dependendo de como a evolução deste ocorre com relação a eles.

O fenômeno descrito anteriormente é conhecido como ressonância, caracterizando-se por perturbar mais intensamente, ou até destruir, a dinâmica de sistemas em torno dos intervalos de frequência no qual a dinâmica do sistema é perturbada por uma força cuja frequência é racional para com a frequência natural do sistema. Para analisar o efeito, uma vantajosa construção é feita para a dinâmica do PCR3C próximo de $L_{4}$, cuja energia é calculada pela expressão (11). Para esta energia total, em especial, é possível se prever para quais valores de massa reduzida $\mu=\mu_{s}$ uma ressonância aparecerá associada à frequência $s$, dada em 16. A expressão que permite prever o valor de $\mu$ associado à uma ressonância do tipo $1 / s$ é 9 :

$$
\mu_{s}=\frac{1}{2}\left(1-\sqrt{\frac{16 s^{2}}{27\left(s^{2}+1\right)^{2}}}\right)
$$

Alguns exemplos de $\mu$ e as suas respectivas razões de ressonância estão representados na Tabela 1.
Tabela 1: Valores de $\mu$ correspondentes a uma ressonância do tipo $1 / s$.

\begin{tabular}{lllllll}
\hline$\mu$ & 0,0135 & 0,0083 & 0,0055 & 0,0039 & 0,0029 & 0,0023 \\
\hline $1 / s$ & $1 / 3$ & $1 / 4$ & $1 / 5$ & $1 / 6$ & $1 / 7$ & $1 / 8$ \\
\hline
\end{tabular}

\section{Simulações}

A fim de verificar resultados discutidos neste trabalho, realizaram-se algumas simulações numéricas de forma a ilustrar o fenômeno de ressonância, destruição de toros e o surgimento do caos no PCR3C. Para tal, empregouse uma versão modificada do algoritmo desenvolvido por Worthington (2012) [7] para simulação da órbita do terceiro corpo a partir da vista paralela ao plano $X Y$ e o concomitante mapeamento da seção de Poincaré. O algoritmo empregue, escrito em $C++$, utiliza o método de Runge-Kutta de quarta ordem para realizar integração numérica. A seção de Poincaré é mapeada segundo o método desenvolvido por Henon 11. Além disso, a saída dos dados e entradas para realizar as simulações foram feitas com OpenGL. As seções de Poincaré de todas as simulações feitas neste trabalho são de $\left(x, p_{x}\right)$ para $y=0$ e $p_{y}>0$.

Na Figura 6 se dispõe o espaço de fase de um sistema com energia total igual a $E=-0,17$. O que se nota da análise direta das representações no plano $X Y$ das órbitas, das Fig 6(A) à 6(E), corresponde exatamente ao que prevê a teoria: superfícies KAM concêntricas existem à direita do mapa. Ao passo que elas se afastam daquilo que seria uma órbita perfeitamente circular, vão se tornando mais deformadas, até que, se encontrarem com uma região de existência de um toro ressonante, destroem-se e dão origem à toros secundários. Esses toros estão associados à Fig.6(D), na qual se nota que a órbita passa a assumir três conformações diferentes. A Fig 6(B), associada aos toros secundários seguintes, possui visivelmente cinco conformações, e assim por diante.

O movimento para além dos limites de irracionalidade das superfícies KAM primárias é registrado pelo permeio de superfícies KAM secundárias e movimento caótico. Assim, na nuvem de pontos ao redor das conformações de órbitas fechadas, existe o movimento completamente 


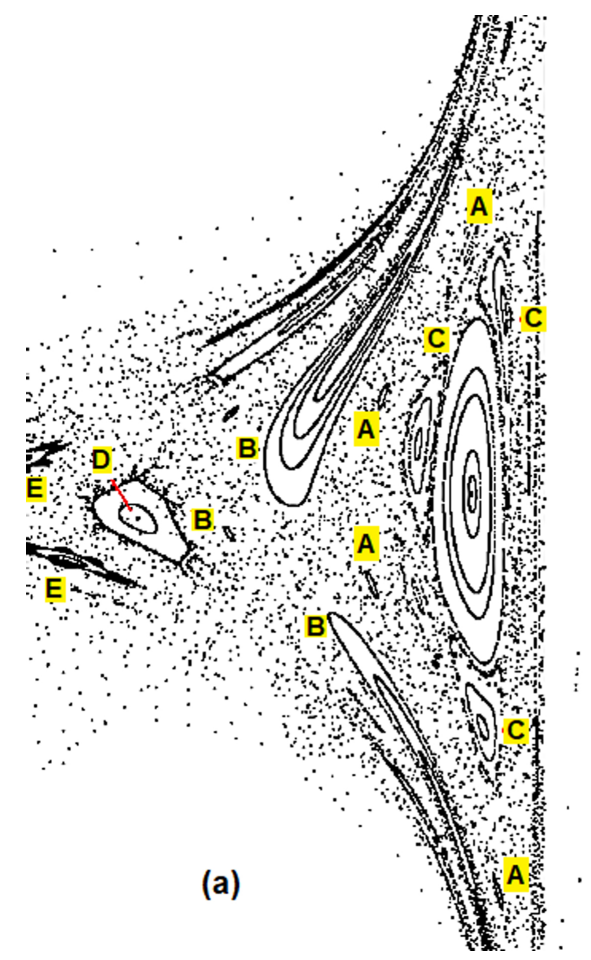

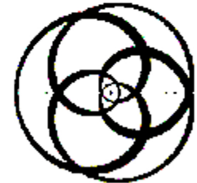

(A)

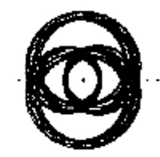

(C)
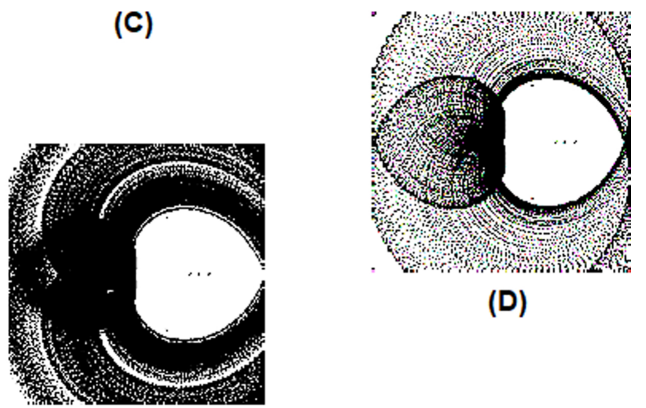

(D)

(E)

Figura 6: (a) Seção de Poincaré $\left(x, p_{x}\right)$ para um sistema com $E=-0,17$. Vistas no plano $\mathrm{XY}$ : (A) órbitas referentes aos toros secundários em A na seção de Poincaré em (a); (B) órbitas referentes aos toros secundários B; (C) órbitas referentes aos toros secundários em $C$ e $(D)$, órbitas referentes aos toros secundários $D$.

errático. Nota-se, inclusive, que nenhuma condição inicial foi capaz de realizar o mapeamento para as pontas extremas do diagrama de fase do sistema.

Retomando a expressão (11), que define a energia de uma órbita em torno do ponto Lagrangeano $L_{4}$, registramse diversos mapeamentos no espaço de fase como função de $\mu$, na Fig.7. Alguns desses pontos foram escolhidos de forma conveniente, a partir da expressão (18) e dos dados disponíveis na Tabela 1, de modo a evidenciar a correlação entre racionalidade, ressonância e a tendência das variáveis de estado.

Para o situação na qual se fasta da condição $r / s=1 / 7$, desaparecem os toros secundários, e isso se verifica em $\mu=0,0025$, na Fig,7, Já para $r / s=1 / 5$, com $\mu$ dado pela Tabela 1, nota-se a formação de cinco ilhas muito pequenas compondo aquilo que seriam os pontos irrotacionais estáveis, da dinâmica do toro primário destruído, mencionado anteriormente. Contudo, o caso mais interessante é aquele para a ressonância $r / s=3 / 10$. Neste se nota a formação de cinco ilhas adjacentes, conforme previa a teoria. Estas ilhas, os toros secundários, são associadas à formação de pontos fixos na evolução de toros - deformados - ressonantes. Além disso, conforme o Teorema KAM, existe certo volume de toros irracionais próximos aos racionais que ainda preservam a topologia fechada.

Existem diversos exemplos reais famosos de como o fenômeno de ressonância e o surgimento de caos agem na dinâmica de sistemas gravitacionais. Em Saturno uma ressonância 2 : 1 com sua lua Mimas produz uma vacância conhecida por Cassimi Division entre os anéis A e B do planeta. Há também as lacunas de Kirkwood, no cinturão de asteroides de Kuiper, nas quais a densidade de corpos cai para valores próximos de zero em determinados pontos, associados às ressonâncias $3: 1,5: 2,7: 3$ e $2: 1$ de Saturno com os asteroides, em relação à órbita em torno do Sol. De fato, o movimento nestas regiões é extremamente sensível às condições iniciais, não permitindo a permanência de um corpo que tivesse sua trajetória ali traçada [12].

Outras questões interessantes à análise de órbitas podem ser evidenciadas. Assim como estudado por Koon (2001) 13, DeSalvo (2006) 14 e Lo (2001) 15, os pontos Lagrangeanos constituem um segmento de pesquisa interessante à transferência orbital, já que podem ser empregues em manobras visando a economia de combustível, como é a análise de otimização de consumo feita por Moore 2009 [16]. Apesar de já serem adotados para uma quantidade razoável de aplicações, o estudo e análise de missões tendo os pontos Lagrangeanos como artifícios de economia de propelente é uma área atual e muito ativa da mecânica orbital.

Dado que a quantidade de propelente que um veículo gasta é proporcional à mudança de velocidade que ele realiza durante a manobra - o impulso - pesquisadores tentam buscar órbitas que reduzam os módulos da diferença de velocidade, de modo a otimizar missões as- 


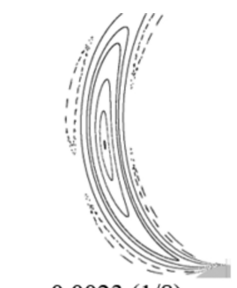
$\mu=0,0023(1 / 8)$

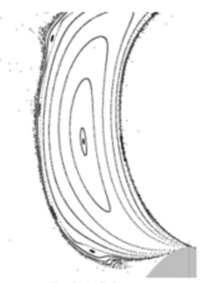

$\mu=0,0050$

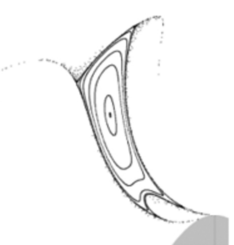

$\mu=0,0083(1 / 4)$
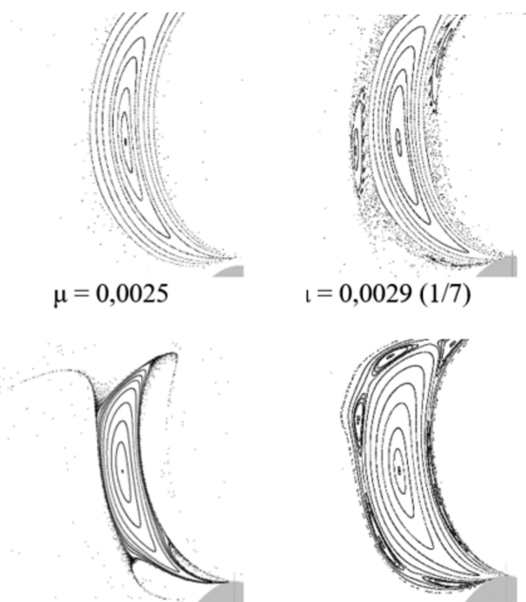

$\mu=0,0055(1 / 5)$

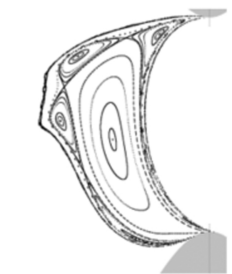

$\mu=0,0100(3 / 10)$

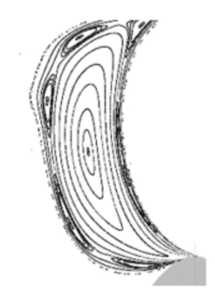

$\mu=0,0065$

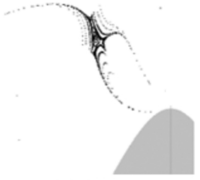

$\mu=0,0130$

Figura 7: Resultados para a seção de Poincaré $\left(x, p_{x}\right)$ entorno do ponto $L_{4}$ para diversos valores de $\mu$.

tronáuticas. Como elucida Koon (2001) 13, os pontos são, de fato, peças fundamentais no avanço deste ramo.

No caso do sistema Terra-Lua-Satélite, imagine que se deseja enviar o último à uma órbita em torno de $L_{4}$ para que, posteriormente, este seja reenviado à um novo destino. Neste exemplo, propondo uma energia total $E=$ -1,6071 para a órbita, almeja-se encontrar condições iniciais que o coloquem, a partir de uma órbita terrestre, em condições de ser capturado por $L_{4}$. Três tentativas foram exemplificadas nas figuras 8 (a), $8(\mathrm{~b})$ e $8(\mathrm{c})$.

A proposta, neste exemplo, foi escolher um nível de energia que limitasse a órbita do terceiro corpo ao interior da estrutura "em ferradura", denotada pela região proi- bida entre $L_{4}, L_{3}$ e $L_{5}$. Com o auxílio desta, permite-se ao mesmo escapar próximo ao segundo primário, como feito nas três situações, nas figuras $8(\mathrm{~b}), 8(\mathrm{c})$ e 8 (d). Contudo, as duas primeiras tentativas ocorreram de modo a mostrar que o corpo apresenta elevada proeminência de abandonar a região entre os primários, casos desinteressantes à proposta. $\mathrm{O}$ que se fez na terceira condição $\left(x_{i}, p_{x, i}\right)$, foi escolher parâmetros que o fizessem ir à $m_{2}$ com tendência a o contornar. Assim, abre-se a possibilidade de empregar uma mudança de órbita com um $\Delta v$ menor na região de inversão contorno do $L_{4}$, fazendo com que o corpo passasse a orbitar $m_{2}$. A manobra original consiste em realizar uma transferência orbital do

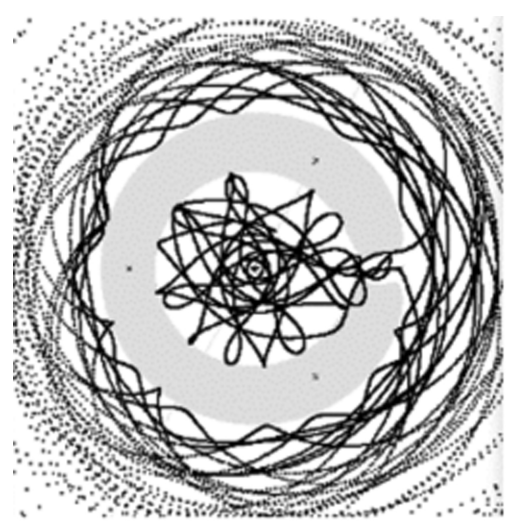

(a)

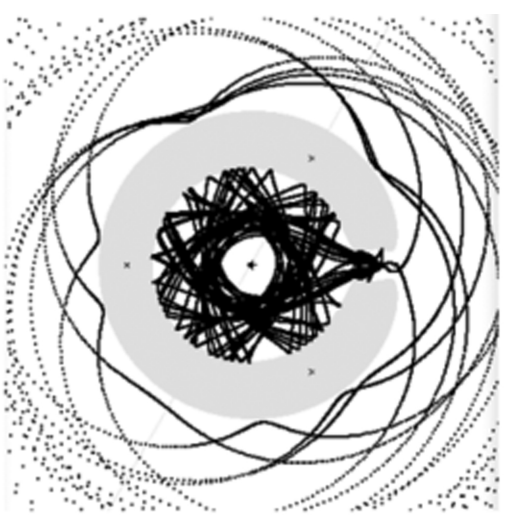

(b)

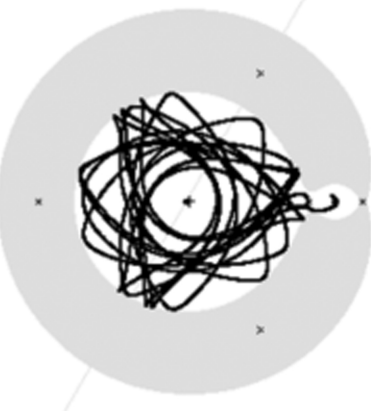

(c)

Figura 8: Vistas do plano da órbita para três tentativas de enviar um satélite de uma órbita terrestre para uma em torno do ponto $L_{4}$; três diferentes valores de $\left(x_{i}, p_{x, i}\right)$ 
tipo hiperbólica-elíptica e, por mais que se empregassem modelos otimizados, como o de Hohmann, não há questionamento de que a situação na qual o contorno é realizado naturalmente será sempre vantajosa. Note que resultados muito díspares são obtidos mesmo em simulações com condições iniciais próximas. Outros aspectos deste problema são estudados por Moore (2009) [16].

Esta proposta de análise, usada como ilustração, serve para demonstrar o problema de transferência de órbitas sobre condições mais próximas das reais e, ao mesmo tempo, evidenciar como os pontos Lagrangeanos e a questão do movimento errático, entre os demais, podem ser empregues em situações reais. Cabe notar que a aplicação do PCR3C tem aplicações semelhantes para problemas de interação atômica, conforme abordado por Pollnow (2011) [10], corroborando a já evidenciada importância do modelo.

\section{Considerações finais}

Neste trabalho se destacou o problema da ressonância no PCR3C e como a dinâmica se dá, no que se refere às condições de equilíbrio e transição para o caos. A perturbação gerada pela existência do terceiro corpo, ainda que não necessariamente destrua os toros no espaço de fase, os deforma, gerando superfícies KAM. O modo como estas evoluem, segundo seu mapa de torção, determina se a dinâmica abandonará sua conformação fechada, sendo destruída ou originando toros secundários permeados por regiões de dinâmica caótica.

O número de superfícies KAM secundárias oriundas da destruição de uma primária, igual a $s$ para um toro ressoante $1: s$, foi evidenciado nas simulações numéricas, corroborando a noção de que o efeito da racionalidade entre de frequência natural do sistema e a da força perturbativa gera em sistemas dinâmicos a tendência ao caos e que, quanto mais irracional um sistema for - mais especificamente, neste trabalho, o PCR3C - menor a sua tendência a ser destruído, também comprovado nas simulações numéricas e levando à máxima: sistemas mais irracionais serão destruídos por último 17.

Esperamos ter contribuído para uma revisão acerca do problema de três corpos, em particular da aproximação PCR3C, que além de sua importância histórica para o desenvolvimento da teoria de sistemas dinâmicos, continua sendo aplicado em estudos atuais sobre a mecânica celeste.

\section{Referências}

[1] L.H.A. Monteiro, Sistemas Dinâmicos (Livraria da Física, São Paulo, 2011), $3^{\text {a }}$ ed.

[2] K.R. Symon, Mecânica (Campus, Rio de Janeiro, 1982).

[3] M.A.M. Aguiar, Tópicos de Mecânica CLássica (Livraria da Física, Campinas, 2010), v. 1.

[4] G. de Felipe, Transferências Orbitais Envolvendo òrbitas do Tipo Halo. Tese de Mestrado, INPE, 2004.
[5] http://farside.ph.utexas.edu/teaching/336k/ Newtonhtml/node121.html, acesso em 03/05/2017.

[6] M.C. Gutzwiller, Chaos in Classical and Quantum Mechanics (Springer, New York, 1990).

[7] J. Worthington, A Study of the Planar Circular Restricted Three Body Problem and Vanishing Twist.Tese de Doutorado, University of Sydney, 2012.

[8] S. Muckerjee, S.K. Palit, S. Kumar and D. K. Bhattacharya, arxiv.org/abs/1409.6738v1 (2014).

[9] K.R. Meyer, G.R. Glen and D. Offin, Introduction to Hamiltonian Dynamical Systems and the $N$-Body Problem (Springer, Cincinati, 2009).

[10] H. Pollnow, Descrição Clássica para a Interação de dois Átomos de Rydberg. Tese de Mestrado, Universidade Federal do Paraná, 2011.

[11] H.A. Oliveira, Revista Brasileira de Ensino de Física 36, 4, 4313 (2014).

[12] C.D. Murray, Solar System Dynamics (Cambridge University Press, Cambridge, 1999), 1st. ed.

[13] W.S. Koon, M. W. Lo, J. E. Marsden e S. D. Ross, Dynamical Systems, the Three-Body Problem and Space Mission Design (Marsden Books, Pasadena, 2011).

[14] http://ccar.colorado.edu/geryon/papers/ Conference/AAS09398.pdf, acesso em 05/04/2017.

[15] M.Lo, S. Ross, in: AIAA Space Conference, Albuberque, 2001, https://arc.aiaa.org/doi/10.2514/6 2001-4768

[16] A. Moore, Two Approaches Utilizing Invariant Manifolds to Design Trajectories for DMOC Optimization, 2009, disponível em http: //www.cds.caltech.edu/ marsden/wiki/uploads/ projects/geomech/CDS205_Project_Moore.pdf

[17] S.D. Prado and M.A.M. de Aguiar, Annals of Phycics 231, 290 (1994). 